\title{
Estimates of aerosol absorption over India using multi-satellite retrieval
}

\author{
D. Narasimhan and S. K. Satheesh \\ Centre for Atmospheric and Oceanic Sciences, Indian Institute of Science, Bangalore, 56012, India \\ Correspondence to: S. K. Satheesh (satheesh@ caos.iisc.ernet.in)
}

Received: 4 March 2013 - Accepted: 23 September 2013 - Published: 22 October 2013

\begin{abstract}
Aerosol absorption is poorly quantified because of the lack of adequate measurements. It has been shown that the Ozone Monitoring Instrument (OMI) aboard EOSAura and the Moderate Resolution Imaging Spectroradiometer (MODIS) aboard EOS-Aqua, which fly in formation as part of the A-train, provide an excellent opportunity to improve the accuracy of aerosol retrievals. Here, we follow a multi-satellite approach to estimate the regional distribution of aerosol absorption over continental India for the first time. Annually and regionally averaged aerosol singlescattering albedo over the Indian landmass is estimated as $0.94 \pm 0.03$. Our study demonstrates the potential of multisatellite data analysis to improve the accuracy of retrieval of aerosol absorption over land.
\end{abstract}

Keywords. Atmospheric composition and structure (aerosols and particles)

\section{Introduction}

Aerosols interact with the Earth's radiation budget directly by absorbing and/or scattering incoming solar as well as outgoing terrestrial radiation (Satheesh and Moorthy, 2005). Indirectly, aerosols can act as cloud condensation nuclei, thereby modifying cloud microphysical properties, altering precipitation processes and influencing the cloud particle interaction with solar and terrestrial radiation. Absorption of radiation by aerosols causes a warming of the lower troposphere and simultaneously cools the Earth's surface. The net effect is believed to be an overall increase in planetary albedo, though not understood well (IPCC, 2007). In recent years, a lot of research has been carried out as a result of recognizing the important influences of aerosols on the Earth's climate. Aerosol absorption is an extremely impor- tant climate-relevant parameter (Hansen et al., 1997; Seinfeld and Pandis, 1998). However, quantifying aerosol absorption is difficult because of the spatial and temporal heterogeneity of aerosol loading, wide variety of sources and composition (Remer et al., 2005). Adding to the complexity, most important absorbing aerosols such as black carbon (anthropogenic) can contaminate other aerosols such as desert dust (natural) and alter the climate impact of the composite aerosol system (Jacobson, 2001; Deepshikha et al., 2004). Even after several extensive investigations and coordinated field campaigns carried out to assess the impact of aerosols on climate, accurate information about the aerosol absorption is sparse (Kaufman et al., 2002; Seinfeld et al., 2004). Moreover, field experiments provide data only for a small region and/or time period, and therefore estimates on a larger scale still rely on chemistry transport models.

There have been several sophisticated satellite sensors dedicated to aerosol studies during the last decade. The Moderate Resolution Imaging Spectroradiometer (MODIS), Multi-angle Imaging Spectroradiometer (MISR) and the Ozone Monitoring Instrument (OMI) are examples. Algorithms for aerosol retrievals using MODIS have been developed and validated over both ocean (Remer et al., 2005; Myhre et al., 2005; Kleidman et al., 2007) and land surfaces (Levy et al., 2007). The uncertainty in these retrievals of aerosol optical depth is still higher over land than over oceans (Levy et al., 2007), owing to uncertainties in land surface reflectance characteristics (Jethva et al., 2009). MISR retrievals have been developed using multiple viewing capability to determine aerosol parameters over ocean and land surfaces, including highly reflective surfaces such as deserts (Kahn et al., 2009). The results have been validated against those from the AERONET (Diner et al., 2005). OMI retrieval is essentially independent of surface reflectance, thereby 
allowing retrievals over both land and ocean (Torres et al., 2007), but is sensitive to the altitude of the aerosol and has a relatively low spatial resolution. However, OMI retrievals only use a limited number of spectral bands compared to dedicated satellites.

Determining aerosol absorption is an important, but complex problem. Presently aerosol absorption is poorly quantified because aerosols vary widely depending on their composition and origin. Carbonaceous aerosols and desert dust are the major light-absorbing aerosols. Adding to the complexity, there exist no direct relationships between aerosol mass, optical depth and the particles' radiative impacts (Seinfeld and Pandis, 1998). A brief review of both in situ and laboratory techniques to measure aerosol absorption has been provided in Torres et al. (2005), and a detailed description is available elsewhere (Weingartner et al., 2003; Arnott et al., 2005). Even though laboratory analysis can provide aerosol absorption in a localized manner, satellite remote sensing stands a better chance (even with the inherent limitations) on a regional basis or in a global scenario. However, few satellite sensors currently make operational retrievals of aerosol absorption, and none of these retrievals is adequately validated. The OMI provides a retrieval of aerosol absorption as a product (Torres et al., 2007). Limited validation exercise indicates that retrieving aerosol absorption from satellite remote sensing still remains a challenge, especially when using a single sensor. Hence, multi-sensor retrievals become increasingly relevant when observations are automatically near-collocated in time and in space, as is the case with A-train sensors (Anderson et al., 2005; Jeong and Hsu, 2008). Recently, Satheesh et al. (2009) made an effort to improve the assessments of aerosol absorption using multiple satellite data, using a combination of OMI and MODIS sensors. In this paper, we have constructed regional distribution of aerosol single-scattering albedo (ratio of scattering to extinction, considered as a measure of aerosol absorption) over the Indian landmass, following the OMI-MODIS joint retrieval algorithm described in Satheesh et al. (2009).

\section{Data and methodology in brief}

MODIS and OMI produce operational aerosol products by using different retrieval methods, which allows combining of their individual advantages. MODIS has 36 channels spanning the spectral range from 0.41 to $14.4 \mu \mathrm{m}$ (Remer et al., 2005). Seven of these channels in the range $0.47-2.13 \mu \mathrm{m}$ are used for retrieval of aerosol products. The MODIS aerosol algorithm consists of two independent algorithms for deriving aerosol properties over land and ocean, respectively. OMI retrieves aerosol products using two algorithms; the near-UV algorithm, which uses two wavelengths in the UV to derive aerosol extinction and absorption optical depth, and a multi-wavelength algorithm that uses up to 19 channels in the $330-500 \mathrm{~nm}$ spectral range to derive aerosol extinction opti- cal depth at several wavelengths (Torres et al., 2007). Both these algorithms are used for aerosol retrieval over both land and ocean. The MODIS land algorithm makes use of the reflectance values in three channels, $0.47,0.66$ and $2.13 \mu \mathrm{m}$, for deriving aerosol products over land (Remer et al., 2005). The surface reflectance in the 0.47 and $0.66 \mu \mathrm{m}$ channels are calculated from the mean reflected radiance in the $2.13 \mu \mathrm{m}$ channel, using empirical relationships (details are available in Remer et al., 2005).

The OMI near-UV algorithm uses measurements made at two wavelengths, 354 and $388 \mathrm{~nm}$ (Torres et al., 1998). The two major advantages of this algorithm are that reflectance of land is very low in UV, which allows retrieval of aerosol properties over a larger variety of surfaces than in visible ones, and secondly, the strong interaction between aerosol absorption and molecular scattering from below the aerosol layer (Torres et al., 2007) allows the estimation of aerosol absorption. Aerosol extinction optical depth (AOD) and aerosol absorption optical depth (AAOD) at $388 \mathrm{~nm}$ are derived using a standard inversion algorithm that uses pre-computed reflectance for a set of assumed aerosol models. The retrieval algorithm is sensitive to aerosol layer height, and hence results are reported for five different assumptions of layer height: at the surface, at 1.5, 3, 6 and $10 \mathrm{~km}$ above surface (Torres et al., 2007). Due to a large footprint of $13 \times 24 \mathrm{~km}^{2}$, OMI pixels are affected by sub-pixel cloud contamination, which leads to overestimation of aerosol extinction optical depth and underestimation of aerosol absorption (Torres et al., 1998, 2007).

As discussed earlier, OMI retrieves both aerosol extinction optical depth (AOD) and absorption aerosol optical depth (AAOD) in the UV channel, while MODIS retrieves AOD in the visible range. While OMI aerosol retrieval is dependent on aerosol layer height, the MODIS retrieval algorithm is insensitive to layer height, but needs to assume a value of single-scattering albedo (or aerosol absorption by assuming aerosol models). Also, owing to their large size $\left(13 \times 24 \mathrm{~km}^{2}\right)$, OMI pixels are susceptible to sub-pixel cloud contamination, whereas MODIS pixels at $500 \mathrm{~m}$ are significantly less affected. Therefore, using a combination of the observations from these two sensors allows us to take advantage of their individual strengths: OMI's sensitivity to aerosol absorption and the better cloud screening of MODIS aerosol products. The methodology proposed in Satheesh et al. (2009) involves using the MODIS-retrieved AOD as input to the OMI retrieval. By doing so, the OMI algorithm will be free to use this information to infer aerosol layer height and hence aerosol absorption. A difficulty however is the extrapolation of MODIS AOD values in the visible range to near-UV, where OMI requires AOD information for its retrieval. The extrapolation method may work well when the aerosol is dominated by large particles, in which case the AOD is weakly wavelength-dependent. However, for fine particles like sulfate or carbonaceous aerosols, an accurate extrapolation is difficult. Satheesh et al. (2009) have tested 
MODIS's ability to estimate AOD in the UV by comparing the extrapolated values with ground-based sun photometer measurements. They have also demonstrated that including information about AOD spectral curvature can greatly improve the linear extrapolation. In this study we have used ground-based aerosol optical depth measurements from the Aerosol Robotic Network (AERONET) and aerosol products retrieved by MODIS and OMI satellite sensors. AERONET provides aerosol optical depths at seven spectral channels, namely $0.34,0.38,0.44,0.50,0.66,0.87$ and $1.020 \mu \mathrm{m}$ (Holben et al., 1998). Under cloud-free conditions, the uncertainty in calculation of AOD is $< \pm 0.01$ for wavelengths $>0.44 \mu \mathrm{m}$ and $< \pm 0.02$ for shorter wavelengths (Holben et al., 1998). AERONET aerosol optical depth (AOD) data are acquired at $15 \mathrm{~min}$ intervals on average.

In summary, the methodology involves the following steps and is demonstrated in Sect. 3.

- Check MODIS's ability to estimate AOD in the UV by comparing the extrapolated values with ground-based sun photometer measurements.

- Use information about AOD spectral curvature to improve the accuracy of UV AOD obtained using extrapolation.

- Use MODIS UV AOD as input in OMI retrieval to constrain the OMI algorithm and obtain SSA.

\section{Results and discussion}

The ability of MODIS to predict AOD values at near-UV can be examined by comparing the extrapolated UV AOD values with sun photometer observations from AERONET. While MODIS achieves an almost complete global coverage once or twice a day, sun photometer retrievals (in this case AERONET) occur several times a day, but only over individual instrumented locations. MODIS pixel values cannot simply be compared directly with AERONET point measurements, because the value contained in an image pixel is representative of the spatial mean over the pixel surface, and so cannot be equated to a point measurement by a sun photometer (Ichoku et al., 2002). In order to achieve a balanced validation, MODIS spatial statistics must be compared with AERONET temporal statistics. To account for both spatial and temporal variabilities of aerosol distribution, the MODIS retrievals at $10 \mathrm{~km} \times 10 \mathrm{~km}$ resolution (level-2 product) and the AERONET direct sun photometer measurements need to be collocated in space and time. The basis for the procedure is to identify within each MODIS aerosol image each pixel falling over a validation point by its longitude and latitude. Then an $\mathrm{N} \mathrm{km} \times \mathrm{N} \mathrm{km}$ subset centered on that pixel is extracted and its mean is computed. The AERONET sun photometer data segment acquired within the $1 \mathrm{~h}$ period centered on the MODIS overpass time is extracted and its mean is computed as described in Ichoku et al. (2002). We have used the level-2 data set from AERONET.

We have estimated MODIS-extrapolated UV AOD values at $0.34 \mu \mathrm{m}$. MODIS provides aerosol optical depth information at three wavelengths, $0.47,0.55$ and $0.66 \mu \mathrm{m}$, in the visible range. The spectral variation of aerosol optical depth follows the Angstrom power law (Angstrom, 1964), and is used to extrapolate visible AODs to estimate UV AOD. A difficulty here is the diverse interaction of different aerosol species with UV and visible wavelengths. Coarse mode-dominated aerosols have negligible spectral AOD variation, whereas fine mode-dominated aerosols (sulfate or carbonaceous aerosols) influence the shorter wavelengths more, thereby leading to a steep spectral slope. Analysis of numerous AOD spectra of many global aerosol types from AERONET data has shown that the departure from the linearity of AOD versus wavelength in log-log scales occurs when fine mode aerosol is dominant, and especially when fine-mode aerosol size increases, typically due to aging (coagulation) or hygroscopic growth (Eck et al., 1999). This indicates that the main reason for the differences in MODISextrapolated and AERONET-measured UV AODs is the dominance of fine-mode aerosols, to which UV wavelengths are more sensitive than visible ones. This problem can be overcome by including information on AOD spectral curvature, which greatly improves the linear extrapolation into UV. This corrects the variable sensitivity of aerosols to different wavelength ranges of the spectra. By plotting the difference between extrapolated and measured AODs at $340 \mathrm{~nm}$ versus the difference between MODIS AODs at 470 and $660 \mathrm{~nm}$, the dependence on the variable sensitivity of aerosol species can be parameterized. This plot yields an empirical equation that is then used to correct the MODIS-extrapolated AOD values at $340 \mathrm{~nm}$. This correction leads to a decrease in RMS (root mean square) errors and gives an improved estimate of MODIS AOD at $340 \mathrm{~nm}$.

After computing the MODIS-extrapolated AOD at $340 \mathrm{~nm}$, the next step is the joint OMI-MODIS retrieval, which involves using MODIS-extrapolated UV AOD to constrain the OMI algorithm. The OMI algorithm uses assumed values of aerosol layer height to constrain AOD and AAOD retrievals. However, if any one of these three parameters is known, then it can be used to estimate the other two. Providing MODIS-extrapolated AOD at $340 \mathrm{~nm}$ as input would thus leave the OMI algorithm free to estimate layer height and AAOD. Also, OMI pixels have large levels of sub-pixel cloud contamination, which causes the retrieval algorithm to overestimate AOD and underestimate single-scattering co-albedo (1-SSA) (Torres et al., 2007). Collocating MODIS and OMI pixels allows MODIS cloud screening to be indirectly applied to OMI data. Thus, collocated OMI pixels, having MODIS counterparts, are much better cloud-screened. OMI provides AOD and AAOD values for five different assumptions of layer height, i.e., at the surface and at 1.5, 3, 6 and $10 \mathrm{~km}$ above the surface. The first step involves using the 


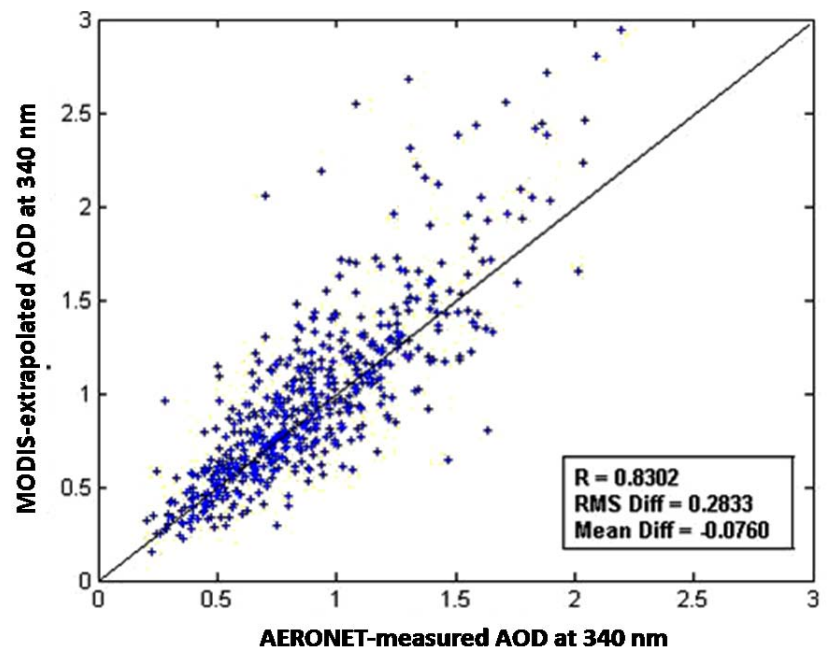

Fig. 1. MODIS-extrapolated AOD at $340 \mathrm{~nm}$ versus AERONETmeasured values.

MODIS-extrapolated AOD at $340 \mathrm{~nm}$ as input in the OMI algorithm and picking the corresponding aerosol layer height. Based on this layer height from OMI-MODIS joint retrieval, the corresponding absorption optical depth (AAOD) is estimated through interpolation.

The collocated MODIS-AERONET data sets at Kanpur $\left(26.5^{\circ} \mathrm{N}, 80.2^{\circ} \mathrm{E}\right)$ consist of MODIS AOD values representative of the spatial mean over $10 \mathrm{~km} \times 10 \mathrm{~km}$ subsets of MODIS data centered at the Kanpur AERONET station, and AERONET values representing the mean of measurements over $\pm 30 \mathrm{~min}$ of MODIS overpass. Figure 1 shows the MODIS-extrapolated AOD at $340 \mathrm{~nm}$ plotted against AERONET-measured values. Data for the period 2004-2010 is used for this purpose. The extrapolated AOD values $(340 \mathrm{~nm})$ show reasonably good agreement with AERONET values at lower optical depths $(<0.5)$, but the scatter increases at higher AOD values. The difference between MODIS-extrapolated and AERONET-measured AOD at $340 \mathrm{~nm}$ can be represented as $\Delta \tau 340$, and the variable sensitivity of aerosols to different ranges of the spectra can be defined by the difference between MODIS AOD at 470 and that at $660 \mathrm{~nm}$ i.e., $\tau 470-\tau 660$, represented by $\varepsilon$. Figure 2 shows the dependence of $\Delta \tau 340$ on $\varepsilon$, and the correlation coefficient is -0.68 .

Figure 2 yielded an empirical equation of the form

$\Delta \tau_{340}=-1.7 \varepsilon+0.18$

This equation has been used to correct the MODISextrapolated AOD values at $340 \mathrm{~nm}$, which has lead to a decrease in the RMS error. The scatter was also seen to decrease considerably. The $\Delta \tau 340$ versus AERONET-measured AOD at $340 \mathrm{~nm}$ (a) before correction and (b) after correction is shown in Fig. 3. The corrected MODIS AODs at $340 \mathrm{~nm}$ are then used as input in the OMI retrieval to determine the corresponding layer height and AAOD values. The layer

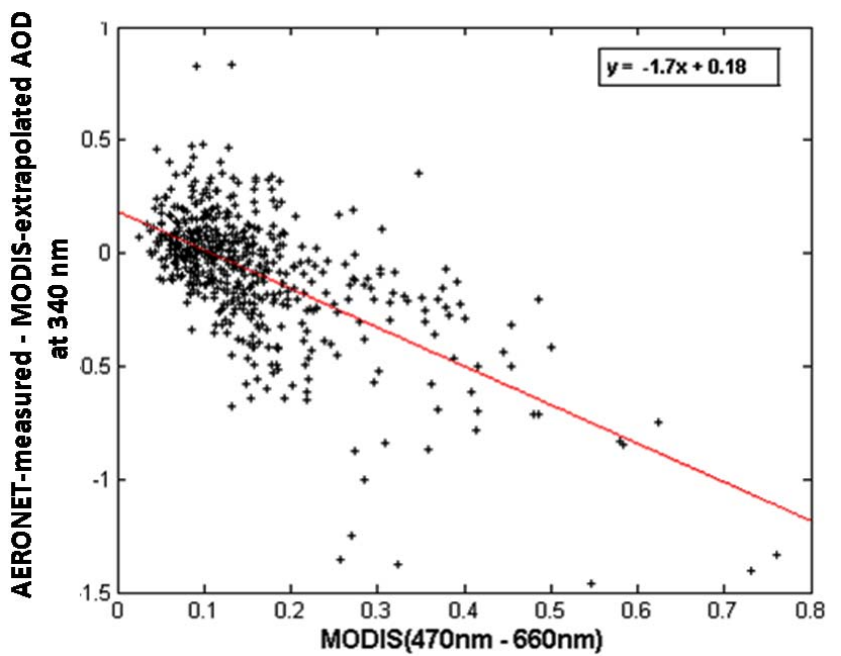

Fig. 2. The dependence of $\Delta \tau 340$ on $\varepsilon$.

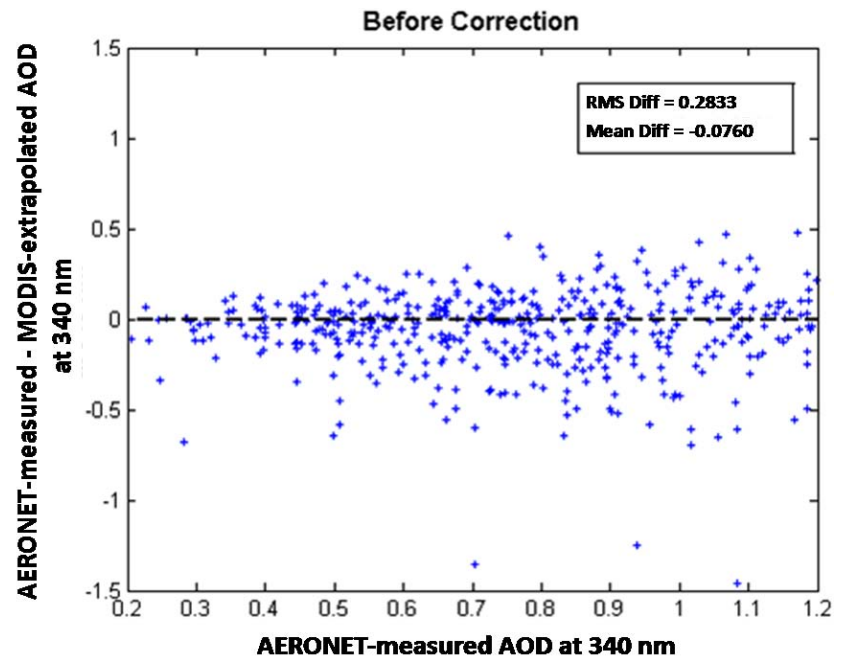

Fig. 3. The $\Delta \tau 340$ versus AERONET-measured AOD at $340 \mathrm{~nm}$ (a) before correction, and (b) after correction.

height was interpolated using the values of AOD provided in the OMI data file at different layer heights. A linear piecewise interpolation scheme was used. It can be perceived as a connect-the-dots process. It uses a different polynomial between each pair of available points for the interpolation, thus making a more accurate estimate of the interpolated value than a simple linear interpolation.

Regional distribution of aerosol SSA is shown in Fig. 4, which shows low SSA over the northern Indian region as compared to southern India. This is due to the increased presence of absorbing aerosols such as black carbon of anthropogenic origin over northern India. These anthropogenic absorbing aerosols are mainly produced by thermal power plants, petrochemical plants and refineries, vehicular pollution, and biomass burning. High SSA values over the coastal 


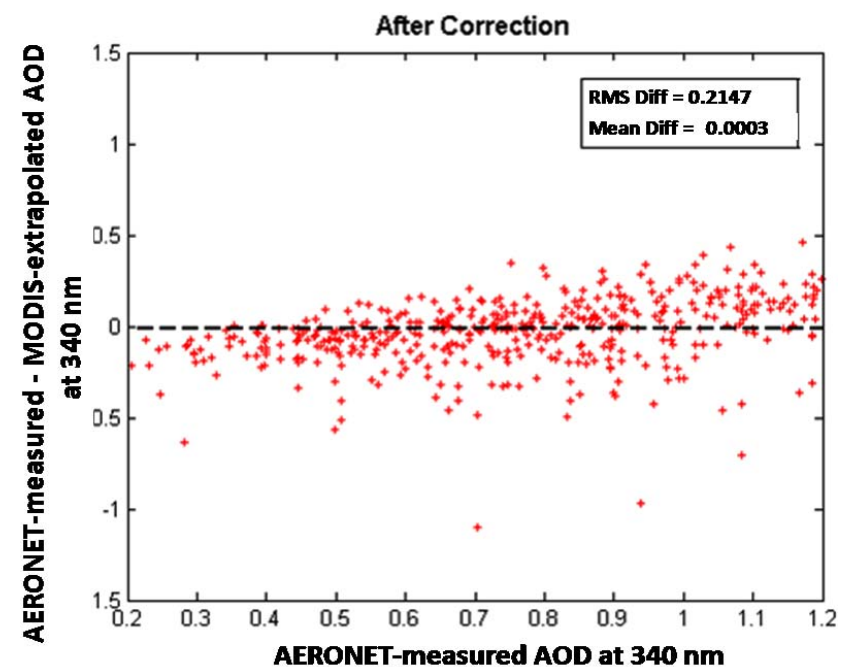

Fig. 4. Regional distribution of aerosol SSA.

areas indicate the presence of scattering aerosols such as sea salt.

The major observations from Fig. 4 are listed below.

1. On average, MODIS-predicted and OMI-standard retrievals of AOD $(0.34 \mu \mathrm{m})$ agree within \pm 0.4 for AODs $<1.5$.

2. OMI-standard retrievals of single-scattering albedo always overestimated OMI-MODIS retrievals of SSA (underestimated absorption) in the range from 0.03 to 0.08 .

3. During January to June (mostly dry months), OMIstandard retrievals of SSA values agreed with OMIMODIS retrievals within +0.05 and overestimated SSA (underestimated absorption) for the rest of the months.

There have been some studies reporting on SSA in the visible wavelengths in this region. Moorthy et al. (2007) used the infrared (IR) radiance $(10.5-12.5 \mathrm{~mm})$ acquired from the METEOSAT-5 satellite ( $\sim 5 \mathrm{~km}$ resolution) to retrieve dust aerosol characteristics over the northwest desert region in India. They inferred single-scattering albedo of dust in the range of 0.88 to 0.94 . Pure dust is non-absorbing. Kaufman et al. (2001), using remote sensing, inferred the SSA of Saharan dust as 0.97 at $0.55 \mathrm{~mm}$, while Haywood et al. (2001) showed that the SSA of Saharan dust at $0.55 \mathrm{~mm}$ is in the range of 0.95 to 0.99 . Dust mixed with other aerosol species such as black carbon (BC) could be the reason for the low single-scattering albedo values over the northwestern desert regions. Another example is Satheesh et al. (2010), where they used an SSA of 0.88 at Bangalore to estimate aerosol radiative forcing. Our study using OMI-MODIS retrieval shows a value of 0.95 . However, it is important to note that measurements of SSA are based on measurements at the surface, and satellite retrievals provide column-integrated SSA values. Further, our study provides SSA at $340 \mathrm{~nm}$ and forcing calculations mentioned above have used SSA in midvisible wavelength. Since the measurements of SSA in UV spectral regions are unavailable over the regions considered, it was not possible to make a direct comparison.

\section{Summary and conclusions}

The Ozone Monitoring Instrument (OMI) aboard NASA's EOS AURA satellite provides aerosol optical depth (AOD) and aerosol absorption optical depth (AAOD) as data products. However, it has to assume aerosol layer height for the retrievals. The Moderate Resolution Imaging Spectroradiometer (MODIS) aboard the EOS TERRA and AQUA satellites provides only aerosol optical depth (AOD), but its retrieval is not sensitive to aerosol layer height. Also, compared to OMI, MODIS aerosol retrieval has a smaller pixel size, thereby having lesser errors due to sub-pixel cloud contamination. In this study we estimate aerosol absorption optical depth (AAOD) and hence single-scattering albedo (SSA) over India using multi-satellite data analysis involving OMI and MODIS. It is seen that this joint retrieval reduces the errors in SSA estimation due to sub-pixel cloud contamination of the large OMI pixels, thereby giving an improved assessment of SSA. Annually and regionally averaged aerosol single-scattering albedo over the Indian landmass is estimated as $0.94 \pm 0.03$. Our study demonstrates the potential of multi-satellite data analysis to improve the accuracy of retrieval of aerosol absorption over land.

Acknowledgements. We thank Brent Holben, NASA GSFC for providing AERONET data at Kanpur, and the site PI and staff for their efforts in establishing and maintaining the Kanpur AERONET site. One of the authors thanks the Department of Science and Technology (DST), New Delhi for the Swarna Jayanti Fellowship award.

Topical Editor Philippe Drobinski thanks one anonymous referee for her/his help in evaluating this paper.

\section{References}

Eck, T. F., Holben, B. N., Reid, J. S., Dubovik, O., Smirnov, A., O'Neill, N.T., Slutsker, I., and Kinne, S.: Wavelength dependence of the optical depth of biomass burning, urban, and desert dust aerosols, J. Geophys. Res., 104, 31333-31349, 1999.

Hansen, J., Sato, M., and Ruedy, R.: Radiative forcing and climate response, J. Geophys. Res., 102, 6831-6864, 1997.

Holben B. N., Eck, T. F., Slutsker, I., Tanre, D., Buis, J. P., Setzer, A., Vermote, E., Reagan, J. A., Kaufman, Y. J., Nakajima, T., Lavenu, F., Jankowiak, I., and Smirnov, A.: AERONET - A federated instrument network and data archive for aerosol characterization, Rem. Sens. Environ., 66, 1-16, 1998. 
Ichoku, C., Chu, D. A., Mattoo, S., Kaufman, Y. J., Remer, L. A., Tanre, D., Slutsker, I., and Holben, B. N.: A spatio-temporal approach for global validation and analysis of MODIS aerosol products, Geophys. Res. Lett., 29, 8006, doi:10.1029/2001GL013206, 2002.

Jeong, M.-J. and Hsu, N. C.: Retrievals of aerosol single-scattering albedo and effective aerosol layer height for biomass-burning smoke: Synergy derived from "A-Train" sensors, Geophys. Res. Lett., 35, L24801, doi:10.1029/2008GL036279, 2008.

Kahn, R. A., Yu, H., Schwartz, S. E., Chin, M., Feingold, G., Remer, L. A., Rind, D., Halthore, R., and DeCola, P.: Introduction, in Atmospheric Aerosol Properties and Climate Impacts, A Report by the US Climate Change Science Program and the Subcommittee on Global Change Research, edited by: Chin, M., Kahn, R. A., and Schwartz, S. E., National Aeronautics and Space Administration, Washington, D.C., USA, 2009.

Kaufman, Y. J., Tanre, D., Dubovik, O., Karnieli, A., and Remer, L. A.: Absorption of sunlight by dust as inferred from satellite and ground-based remote sensing, Geophys. Res. lett., 28, 14791482, doi:10.1029/2000GL012647, 2001.

Kaufman, Y. J., Tanre, D., and Boucher, O.: A satellite view of aerosols in the climate system, Nature, 419, 215-223, doi:10.1038/nature01091, 2002.

Rember, L. A., Kaufman, Y. J., Tanre, D., Mattoo, S., Chu, D. A., Martins, J. V., Li, R. R., Ichoku, C., Levy, R. C., Kleidman, R. G., Eck, T. F., Vermote, E., and Holben, B. N.: The MODIS aerosol algorithm, products and validation, J. Atmos. Sci., 62, 947-973, doi:10.1175/JAS3385.1, 2005.

Satheesh, S. K. and Krishna Moorthy, K.: Radiative Effects of Natural Aerosols: A Review, Atmos. Environ., 39, 2089-2110, 2005.

Satheesh, S. K., Torres, O. Remer, L. A., Babu, S. S., Vinoj, V., Eck, T. F., Kleidman, R. G., and Holben, B. N.: Improved assessment of aerosol absorption using OMI-MODIS joint retrieval, J. Geophys. Res., 114, D05209, doi:10.1029/2008JD011024, 2009.
Satheesh, S. K., Vinoj, V., and Krishnamoorthy, K.: Assessment of aerosol radiative impact over oceanic regions adjacent to Indian Subcontinent using multi-satellite analysis, Adv. Meteorol., 2010, 139186, doi:10.1155/2010/139186, 2010.

Seinfeld, J. H. and Pandis, S. N.: Atmospheric Chemistry and Physics: From Air Pollution to Climate Change, 1326 pp., Wiley, New York, 1998.

Seinfeld, J. H., Carmichael, G. R., Arimoto, R., Conant, W. C., Brechtel, F. J., Bates, T. S., Cahill, T. A., Clarke, A. D., Doherty, S. J., Flatau, P. J., Huebert, B. J., Kim, J., Markowicz, K. M., Quinn, P. K., Russell, L. M., Russell, P. B., Shimizu, A., Shinozuka, Y., Song, C. H., Tang, Y., Uno, I., Vogelmann, A. M., Weber, R. J., Woo, J.-H., and Zhang, X. Y.: ACE-ASIA: Regional climatic and atmospheric chemical effects of Asian dust and pollution, B. Am. Meteorol. Soc., 85, 367-380, doi:10.1175/BAMS85-3-367, 2004.

Torres, O., Bhartia, P. K., Herman, J. R., and Ahmad, Z.: Derivation of aerosol properties from satellite measurements of backscattered ultraviolet radiation. Theoretical Basis, J. Geophys. Res., 103, 17099-17110, doi:10.1029/98JD00900, 1998.

Torres, O., Tanskanen, A., Veihelmann, B., Ahn, C., Braak, R., Bhartia, P. K., Veefkind, P., and Levelt, P.: Aerosols and surface UV products from Ozone Monitoring Instrument observations: An overview, J. Geophys. Res., 112, D24S47, doi:10.1029/2007JD008809, 2007.

Torres, O., Bhartia, P. K., Sinyuk, A., Welton, E. J., and Holben, B.: Total Ozone Mapping Spectrometer measurements of aerosol absorption from space: Comparison to SAFARI 2000 ground-based observations, J. Geophys. Res., 110, D10S18, doi:10.1029/2004JD004611, 2005.

Weingartner, E., Saathoff, H., Schnaiter, M., Streit, N., Bitnar, B., and Baltensperger, U.: Absorption of light by soot particles: Determination of the absorption coefficient by means of aethalometers, J. Aerosol Sci., 34, 1445-1463, doi:10.1016/S00218502(03)00359-8, 2003. 